\title{
Patient and public involvement in the development of healthcare guidance: An overview of current methods and future challenges
}

Ahmed Rashid ${ }^{1 *}$, Victoria Thomas ${ }^{1}$, Toni Price ${ }^{1}$, Gillian Leng ${ }^{1}$

${ }^{1}$ National Institute for Health and Care Excellence (NICE), 1st Floor, 10 Spring Gardens, London SW1A 2BU, UK.

*corresponding author: ahmed.rashid@doctors.org.uk

\section{Abstract}

Clinical guidelines and health technology assessments are valuable instruments to improve the quality of healthcare delivery and aim to integrate the best available evidence with real-world, expert context. The role of patient and public involvement in their development has grown in recent decades and this article considers the international literature exploring aspects of this participation, including the integration of experiential and scientific knowledge, recruitment strategies, models of involvement, stages of involvement, and methods of evaluation. These developments have been underpinned by the parallel rise of public involvement and evidence based medicine as important concepts in health policy. Improving the recruitment of guideline group chairs, widening evidence reviews to include patient preference studies, adapting guidance presentation to highlight patient preference points and providing clearer instructions on how patient organisations can submit their intelligence are emerging proposals that may further enhance patient and public involvement in their processes. 


\section{Key Points}

- The role of patient and public involvement in the development of clinical guidance and standards has grown in recent decades

- A number of issues have been considered in the international literature including the integration of experiential and scientific knowledge, recruitment strategies, models of involvement, stages of involvement, and methods of evaluation

- A variety of suggestions have emerged considering ways to advance this involvement and make it more meaningful including acknowledging and addressing barriers and measuring impact.

\section{Background}

In recent decades, guidelines and health technology assessments have become an increasingly important part of healthcare policy and practice around the world [1-3]. Rising healthcare costs, expensive technologies, variations in service delivery among providers and the intrinsic desire of clinicians to offer the best possible care are all factors that have contributed to this rise. Clinical guidelines are systematically developed statements that are used to guide healthcare decisions across various settings [4, 5]. Health technology assessments are research-based, practice oriented assessments of healthcare technologies that support policymakers to introduce new technologies to the health system effectively [6]. Quality indicators, meanwhile, are measurable items that facilitate improvement in the quality of healthcare practices and services [3]. They all share a common approach of robustly evaluating evidence and expert knowledge to formulate practical recommendations to achieve improvements in healthcare delivery.

In order to support guideline producing organisations to reach these important goals, there has been much international interest in how to improve the quality of guidance through standardised methodologies and critical assessment tools [7]. A systematic review assessed 24 such assessment instruments from eight different countries, 
concluding that the Appraisal of Guidelines for Research and Evaluation (AGREE) instrument was the highest quality overall [8]. A subsequent systematic review in 2012 used the AGREE instrument to assess the quality of clinical guidelines developed in Europe since 2000, finding that there was considerable room for methodological improvements [9].

An aspect of guideline quality that has received particular attention is the extent to which patients and public are involved in the development process. It has been suggested that this involvement has the potential to increase the relevance and acceptability of recommendations as patients are likely to have fewer alliances than healthcare professionals [10]. However, various barriers to meaningful participation have also been cited, including the hierarchical nature of healthcare professions and perceived bias in individual viewpoints [11], leading to limited opportunities for input and influence. The lack of empirical research about the measurable impact of patient and public involvement (PPI) is noteworthy [12] and the diversity of opinion about optimal involvement strategies highlights that although PPI is taking place worldwide in different forms, it remains an emergent field.

This review seeks to summarise the current practice of PPI in healthcare guidance development and highlight future challenges. Database searches and manual reference tracking were used to identify editorials and primary qualitative and quantitative research exploring patient involvement in healthcare guidance. Decisions about literature inclusion and the shaping of key themes were made through consensus meeting of the reviewers.

\section{Stages of involvement}

The production of guidance can be a lengthy process and public involvement can take place at multiple stages. Topic selection is the obvious first step, with input at this stage considered valuable for both clinical guidelines and health technology assessments [13-16]. Similarly, participation in deciding the scope is deemed important as it is an opportunity to "set the agenda and determine the rules and the players" [17]. Involvement in the formation of recommendations is widely advocated $[18,19]$, along with opportunities to comment on draft versions $[15,18]$. 
Patient and public members may also be included in implementation activities [13, $20,21,22]$, including working with the media and promoting guidance at national and regional levels [23]. There is a strong body of support calling for patient and public involvement throughout the guideline development process [18, 22, 24, 25].

\section{The integration of experiential and scientific knowledge}

The challenge of incorporating patient perspectives alongside scientific evidence reflects the conceptual conflicts between evidence based medicine (EBM), which relies on objective and robust data, and PPI, which is intrinsically based on the experiences of individuals. It has been suggested that this may be resolved by providing active support for patient and public members to engage in guidance development. For example, the use of scientific and medical terminology by guideline developers and health professionals has been identified as a particular barrier for patient and public participants $[13,14,26,27,28,29,30]$ and there has been reported uncertainty about the extent to which they should be able to interpret scientific evidence [14, 27]. Providing critical appraisal training for patient and public participants has been widely endorsed [15, 17, 18, 20, 21, 23, 27, 30, 31, 32], although it has been found to be resource intensive [23, 27]. However, a contrasting perspective is that the unique benefit of PPI comes from experiential learning and therefore academic skills are not relevant [28] and indeed, it had been argued that they actually weaken participation by reducing the uniqueness of "true" patients "in the wild" [33].

Guideline development is typically performed by a group that includes a chair, healthcare professionals from different backgrounds and technical staff from the guideline producing organisation [34], along with patient and public members. The role of the chair has been widely recognised as being important for effective PPI to occur $[20,23,29,35,36]$. Although chairs seem to have discordant opinions how important active PPI is [36], it has been suggested that they could play an important empowering role, with specific proposals including the use of a psychologist chair to ensure effective group dynamics [29] and a reminder item on the agenda to consider 
patient perspectives in each meeting [20]. There was some concern that patient and public members may not be actively included in these groups leading to infrequent and inappropriate contributions [19,27], although their presence was felt to be vital by others to make discussions less "physician-centric" [24] and keep a focus on the right questions.

There has been considerable interest in understanding how patient preferences can be better incorporated into healthcare guidance. Widening search strategies to include qualitative research $[13,15,21,24,28,31,37]$, developing new methods to synthesise patient preference knowledge $[15,38,39]$ and using social scientists to review this evidence [21, 37] have all been widely supported. There is, however, an impression that this type of evidence is deemed less credible by guideline developers and concerns about the extent to which narrative evidence fits into the traditional hierarchy of EBM [16, 23, 24, 35, 40]. An additional related mechanism to include these perspectives is the addition of relevant key questions for guideline development groups to consider.

In the presentation of guidance, a greater openness about uncertain recommendations may help emphasise patient preferences with calls for less firm recommendations [41] and more use of menus to present multiple possible management strategies [26, 42]. It was also felt that professional versions of guidelines could be improved by signalling recommendations that require shared decision making and providing links directly to decision aids from the guideline [24, $38,31]$.

\section{Recruitment}

There has often been a lack of clarity about whether lay members should be representing themselves or the wider public, with expectations often being unclear $[14,15,16,33,36,38,43]$. Although there have been suggestions that input should be exclusively from an individual or general public perspective [25, 33], there seems to be recognition that in reality, this is a complex distinction to make [36]. Views about the role of patient organisations have been divergent. Whilst there is recognition that they can play a variety of roles including submitting evidence and 
nominating or recruiting members [16, 23], concerns have been raised about the fact that some organisations are dependent on industry funding.

The difficulty recruiting a diverse range of participants has been noted, with challenges to recruit representation across age, gender, ethnicity, education and socioeconomic dimensions [16, 22, 38, 44]. Stigma is an important consideration when recruiting for conditions such as sexual diseases and HIV [45]. Some organisations have opted to produce mini 'job descriptions' $[23,38]$ with description of the role, task and skills needed. Although these have helped to ensure that participants are clear about their roles and have largely been deemed helpful [23], the presence of scientific literacy as a desirable trait has been criticised as a barrier to achieving genuine representation [42].

\section{Model of involvement}

In her seminal paper on citizen involvement, Sherry Arnstein conceptualised a ladder of involvement with 8 steps representing increasingly significant levels of involvement in decision-making [46]. Subsequent adaptations of the model have focussed particularly on flow of information and have distinguished between organisations that use unilateral methods of communication (such as consultation or public information) and those that use the preferable bilateral approaches (such as active group participation) [17, 31]. Although posting guidance online for public comment is a broad and open avenue, it relies on engagement with long documents that contain significant amounts of technical information and jargon.

Public advisory committees such as the Citizen's Council of the National Institute for Health and Care Excellence (NICE) [13, 15, 20, 31, 47] and the Ontarian Health Technology Advisory Committee (OHTAC) [44, 48] in Canada are generally highly regarded, although the lack of direct input and public will to engage have been noted as limitations $[13,47]$. The use of priority-setting exercises are a further means to seek public advice but their role is limited by the high amount of resources that it requires. 
The composition of guidance producing groups is fundamental, with many organisations including one or two lay members routinely [21, 23, 36, 39]. This direct involvement and opportunity for discussion has been described as an essential feature [24], although contributions can be infrequent and active participation relies on a supportive culture [30]. In addition to direct involvement in groups, the use of structured peer-facilitation and flipcharts has been found useful [30], although such workshops have proven resource intensive [27]. Importantly, the information gathered from these workshops is typically fed back to the guideline working group by a member of the support team, which means there is no direct interaction between the two groups and no means for two-way "knowledge exchange" to occur $[19,49]$.

Although patient organisations are generally able to submit evidence to inform guidance development $[16,23,26]$, there is concern about how it is handled and utilised $[13,40]$. These organisations may be able to better use their networks and knowledge if there was a clearer route for them to contribute their data [50]. Interest in using novel ways of engaging the public, such as online platforms and social media is also rising [31]. However, there is not yet a clear mechanism by which these forms of evidence can be quality assured and synthesised into a form that can usefully inform guidance.

\section{Evaluation}

It has widely been suggested that involvement has intrinsic value by promoting democracy, redistributing power and allowing patients to influence the health system $[17,28,30,42,49]$. Thus, PPI may be considered a goal in itself that does not require justification and cannot be opposed, other than on methodological grounds [42]. Others have argued that it is important in order to gain legitimacy [20, 25, 51], increase responsiveness to public need [16] and make guidance easier to implement $[30,49]$.

Although the lack of formal evaluation of PPI has been criticised [15, 51], there has been recognition that randomised-controlled trials (RCTs), for example, would be "very difficult if not impossible" to conduct in this area [28]. Indeed, a Cochrane 
review in 2006 found no published trials evaluating patient involvement in clinical guidelines [12] and although none appear to have been published since, a more recent cluster RCT across 6 Canadian communities was promisingly able to demonstrate that patient involvement can change priorities for healthcare improvement at the population level [52]. Of note, there is a lack of published evidence about the experiences of patients and public members involved in healthcare guidance and this may be an important topic for future research.

Various instruments have been designed to evaluate guidance quality and although the inclusion of a patient involvement dimension in the AGREE checklist has been welcomed [28], it may not differentiate meaningful involvement from tokenism and has been described as a "blunt instrument" [33] in assessing how patient-centred guidance is. The work of international networks has enhanced patient involvement [51], although even greater international collaboration would allow organisations to further share learning and expertise $[38,53]$. Indeed, criticisms of exclusivity and tokenism have also been directed to PPI in other areas of healthcare including research and improvement activities and models of equitable partnership working are being developed [54].

\section{Conclusions}

The concurrent rise in prominence of EBM and patient involvement in health policy in recent decades has been the backdrop to the evolution of PPI in healthcare guidance around the world. The inevitable tensions between these two conceptual paradigms have given rise to complex challenges faced by guideline developers and barriers to designing processes that facilitate meaningful and effective involvement.

The role of a guideline group chair is particularly important and a greater emphasis on ability to facilitate supportive discussions when electing new chairs may help to improve this. Although there is no consensus on a single involvement strategy, there are circumstances where both individual and broader societal perspectives are beneficial. Areas that require unique perspectives such as clinical guidelines may benefit more from patients or carers with experiences of a particular condition, 
whereas members of standing committees for health technology assessment or indicators may require public members with societal perspectives.

Widening search strategies in evidence reviews to include patient preference literature has the potential to significantly increase applicability by incorporating a broader collection of perspectives. However, this is likely to require a fundamental change for guideline developers and necessitate developmental work to establish new methods of knowledge synthesis, employment of social scientists to contribute to evidence reviews and significant financial investment. Changing the format of guidance to highlight the relative uncertainty of recommendations and links to decision tools is also an important consideration for the future.

Healthcare guidance and indicators continue to be a key method to improve health systems around the world. Specifically, they improve the quality and experience that patients and the public receive from healthcare and ensuring their representation in their development is therefore fundamental, whether for reasons of democracy or improved quality. This paper provides policymakers and health guidance producers with a review of current practices and future challenges relating to PPI. Although much progress has been made, further improvements are needed in order to enable guideline production that allows meaningful input through both preference information and direct involvement.

\section{Conflicts of interest}

VT, TS and GL are employed by the National Institute of Health and Care Excellence (NICE), who produce guidelines and quality standards. AR is a clinician in the UK National Health Service who completed a fellowship at NICE in 2015.

\section{Acknowledgements}

$\mathrm{AR}, \mathrm{VT}$ and GL conceived and designed the article. AR and TS completed database and manual searches to identify the literature. AR and VT developed the outline and headings of the paper. AR wrote the first draft and VT, TS and GL critically revised it. All authors approved the final version of the manuscript. 


\section{References}

1. Woolf SH, Grol R, Hutchinson A, Eccles M, Grimshaw J. Potential benefits, limitations, and harms of clinical guidelines. BMJ : British Medical Journal. 1999;318(7182):527-530.

2. Grol R, Wensing M, Eccles M. Improving patient care: the implementation of change in clinical practice. New York: Elsevier Butterworth Heinemann, 2005.

3. Boulkedid R, Abdoul H, Loustau M, Sibony O, Alberti C Using and Reporting the Delphi Method for Selecting Healthcare Quality Indicators: A Systematic Review. PLoS ONE. 2011; 6(6): e20476.

4. Jackson R, Feder G. Guidelines for clinical guidelines. BMJ. 1998; 15; 317(7156):427-8.

5. Feder G, Eccles M, Grol R, Griffiths C, Grimshaw J. Clinical guidelines: Using clinical guidelines. BMJ. 1999; 318(7185), 728.3

6. Cavazza M, Jommi C. Stakeholders involvement by HTA Organisations: why is so different? Health Policy. 2012 May;105(2-3):236-45.

7. Shaneyfelt TM, Mayo-Smith MF, Rothwangl J. Are Guidelines Following Guidelines?: The Methodological Quality of Clinical Practice Guidelines in the Peer-Reviewed Medical Literature. JAMA 1999;281(20):1900-1905.

8. Vlayen J, Aertgeerts B, Hannes K, Sermeus W, Ramaekers D. A systematic review of appraisal tools for clinical practice guidelines: multiple similarities and one common deficit. International Journal for Quality in Health Care 2005;17:235-42.

9. Knai C, Brusamento S, Legido-Quigley H et al. Systematic review of the methodological quality of clinical guideline development for the management of chronic disease in Europe. Health Policy. 2012 Oct;107(2-3):157-67.

10. Crawford MJ, Rutter D, Manley C, Weaver T, Bhui K, Fulop N, et al. Systematic review of involving patients in the planning and development of health care. BMJ 2002;325:1263-7.

11. Boote J, Telford R, Cooper C. Consumer involvement in health research: a review and research agenda. Health Policy 2002;61:213-36.

12. Nilsen ES, Myrhaug HT, Johansen M, Oliver S, Oxman AD. Methods of consumer involvement in developing healthcare policy and research, clinical practice guidelines and patient information material. Cochrane Database Syst Rev. 2006 Jul 19;(3):CD004563.

13. Gagnon MP, Desmartis M, Lepage-Savary D, Gagnon J, St-Pierre M, Rhainds M et al. Introducing patients' and the public's perspectives to health technology assessment: A systematic review of international experiences. Int J Technol Assess Health Care. 2011 Jan;27(1):31-42.

14. Hailey D, Werkö S, Bakri R, Cameron A, Göhlen B, Myles S et al. Involvement of consumers in health technology assessment activities by Inahta agencies. Int J Technol Assess Health Care. 2013; 29(1):7983.

15. Kelson M, AkI EA, Bastian H, Cluzeau F, Curtis JR, Guyatt G et al. Integrating values and consumer involvement in guidelines with the patient at the center: article 8 in Integrating and coordinating efforts in COPD guideline development. An official ATS/ERS workshop report. Proc Am Thorac Soc. 2012 Dec;9(5):262-8.

16. Quennell P. Getting their say, or getting their way? - Has participation strengthened the patient "voice" in the National Institute for Clinical Excellence? J Manag Med. 2001;15(3):202-19 Roman BR, Feingold J. Patient-centered Guideline Development Best Practices Can Improve the Quality and Impact of Guidelines. Otolaryngology--Head and Neck Surgery. 2014; 151(4), 530-532. 
17. Bastian $\mathrm{H}$. Raising the standard: practice guidelines and consumer participation. Int $\mathrm{J}$ Qual Health Care. 1996 Oct;8(5):485-90.

18. Roman BR, Feingold J. Patient-centered Guideline Development Best Practices Can Improve the Quality and Impact of Guidelines. Otolaryngology--Head and Neck Surgery. 2014; 151(4), 530-532.

19. Tong A, Lopez-Vargas $P$, Howell M, Phoon R, Johnson D, Campbell D et al. Consumer involvement in topic and outcome selection in the development of clinical practice guidelines. Health Expect. 2012 Dec;15(4):410-23.

20. Barham L. Public and patient involvement at the UK National Institute for Health and Clinical Excellence. Patient. 2011;4(1):1-10.

21. Díaz Del Campo P, Gracia J, Blasco JA, Andradas E. A strategy for patient involvement in clinical practice guidelines: methodological approaches. BMJ Qual Saf. 2011 Sep;20(9):779-84.

22. Facey KM, Hansen HP. Patient-focused HTAs. Int J Technol Assess Health Care. 2011 Oct;27(4):2734.

23. Kelson, M. The NICE patient involvement unit. Evidence-based healthcare and public health. 2005; 9(4), 304-307.

24. Krahn M, Naglie G. The next step in guideline development: incorporating patient preferences. JAMA. 2008 Jul 23;300(4):436-8.

25. Bridges JF, Jones C. Patient-based health technology assessment: a vision of the future. Int J Technol Assess Health Care. 2007; 23(1):30-5.

26. Kelson M. Patient involvement in clinical guideline development-where are we now?. The Journal of Clinical Governance. 2001; 9.4: 169-174.

27. van Wersch A, Eccles M. Involvement of consumers in the development of evidence based clinical guidelines: practical experiences from the North of England evidence based guideline development programme. Qual Health Care. 2001 Mar;10(1):10-6.

28. van de Bovenkamp HM1, Trappenburg MJ. Reconsidering patient participation in guideline development. Health Care Anal. 2009 Sep;17(3):198-216.

29. Harding E, Pettinari CJ, Brown D, Hayward M, Taylor C. Service user involvement in clinical guideline development and implementation: learning from mental health service users in the UK. Int Rev Psychiatry. 2011 Aug;23(4):352-7.

30. Légaré F, Boivin A, van der Weijden T, Pakenham C, Burgers J, Légaré J et al. Patient and public involvement in clinical practice guidelines: a knowledge synthesis of existing programs. Med Decis Making. 2011 Nov-Dec;31(6):E45-74.

31. Whitty JA. An international survey of the public engagement practices of health technology assessment organizations. Value Health. 2013 Jan-Feb;16(1):155-63.

32. Pohontsch NJ, Herzberg H, Joos S, Welti F, Scherer M, Blozik E. The professional perspective on patient involvement in the development of quality indicators: a qualitative analysis using the example of chronic heart failure in the German health care setting. Patient Prefer Adherence. 2015 Jan 22;9:151-9.

33. van de Bovenkamp HM, Zuiderent-Jerak T. An empirical study of patient participation in guideline development: exploring the potential for articulating patient knowledge in evidence-based epistemic settings. Health Expect. 2013 May 2. doi: 10.1111/hex.12067. 
34. Shekelle, PG, Woolf SH, Eccles M, Grimshaw J. Clinical guidelines: developing guidelines. BMJ. 1999; 318(7183), 593.

35. van der Ham AJ, Shields LS, van der Horst R, Broerse JE, van Tulder MW. Facilitators and barriers to service user involvement in mental health guidelines: lessons from the Netherlands. Adm Policy Ment Health. 2014 Nov;41(6):712-23.

36. Lopes E, Street J, Carter D, Merlin T. Involving patients in health technology funding decisions: stakeholder perspectives on processes used in Australia. Health Expect. 2015 Feb 21. doi: 10.1111/hex.12356.

37. Facey K, Boivin A, Gracia J, Hansen HP, Lo Scalzo A, Mossman J et al. Patients' perspectives in health technology assessment: a route to robust evidence and fair deliberation. Int J Technol Assess Health Care. 2010 Jul;26(3):334-40.

38. Boivin A, Currie K, Fervers B, Gracia J, James M, Marshall C et al. Patient and public involvement in clinical guidelines: international experiences and future perspec Qual Saf Health Care. 2010 Oct;19(5):e22.

39. Chong CA, Chen IJ, Naglie G, Krahn MD. How well do guidelines incorporate evidence on patient preferences? J Gen Intern Med. 2009 Aug;24(8):977-82.

40. Quennell, P. Getting a word in edgeways? Patient group participation in the appraisal process of the National Institute for Clinical Excellence. Clinical Governance: An International Journal. 2003; 8(1), 39 45.

41. Montori VM, Brito JP, Murad MH. The Optimal Practice of Evidence-Based Medicine: Incorporating Patient Preferences in Practice Guidelines. JAMA. 2013 Dec 18;310(23):2503-4.

42. Boivin A, Green J, van der Meulen J, Légaré F, Nolte E. Why consider patients' preferences? A discourse analysis of clinical practice guideline developers. Med Care. 2009 Aug;47(8):908-15.

43. Gauvin FP, Abelson J, Giacomini M, Eyles J, Lavis JN. "It all depends": Conceptualizing public involvement in the context of health technology assessment agencies. Soc Sci Med. 2010 May;70(10):1518-26.

44. Bombard Y, Abelson J, Simeonov D, Gauvin FP. Eliciting ethical and social values in health technology assessment: A participatory approach. Soc Sci Med. 2011 Jul;73(1):135-44.

45. Clarke J, Chuter A. The BASHH public panel: climbing the ladder of involvem Sex Transm Infect. 2014 $\operatorname{Mar} ; 90(2): 83$.

46. Arnstein SR. A ladder of citizen participation. Journal of the American Institute of planners. 1969; 35(4), 216-224.

47. Syrett K. Deconstructing Deliberation in the Appraisal of Medical Technologies: NICEly Does it?. The Modern Law Review. 2006; 69(6), 869-894.

48. Abelson J, Bombard Y, Gauvin FP, Simeonov D, Boesveld S. Assessing the impacts of citizen deliberations on the health technology process. Int J Technol Assess Health Care. 2013 Jul;29(3):282-9.

49. Pittens CA, Vonk Noordegraaf A, van Veen SC, Anema JR, Huirne JA, Broerse JE. The involvement of gynaecological patients in the development of a clinical guideline for resumption of (work) activities in the Netherlands. Health Expect. 2013 Aug 29. doi: 10.1111/hex.12121.

50. Moreira T. Understanding the role of patient organisations in health technology assessment. Health Expect. 2014 Dec 14. doi: 10.1111/hex.12325. 
51. Gauvin FP, Abelson J, Giacomini M, Eyles J, Lavis JN. Moving cautiously: Public involvement and the health technology assessment community. Int J Technol Assess Health Care. 2011 Jan;27(1):43-9.

52. Boivin A, Lehoux P, Lacombe R, Burgers J, Grol R. Involving patients in setting priorities for healthcare improvement: a cluster randomized trial. Implement Sci. 2014 Feb 20;9:24.

53. Kötter T, Schaefer FA, Scherer M, Blozik E. Involving patients in quality indicator development - a systematic review. Patient Prefer Adherence. 2013;7:259-68.

54. Ocloo J, Matthews R. From tokenism to empowerment: progressing patient and public involvement in healthcare improvement. BMJ Qual Saf. 2016 Aug;25(8):626-32. 